\title{
Physical modelling of backward erosion piping in foundation beneath levee
}

\author{
N. Koito \\ Mitsubishi Heavy Industries, Yokohama, Japan (Formerly, Tokyo Institute of Technology, Tokyo, Japan) \\ K. Horikoshi \& A. Takahashi \\ Tokyo Institute of Technology, Tokyo, Japan
}

\begin{abstract}
Centrifuge model tests are performed to observe piping progression in foundation beneath levee and to examine influence of repeated seepage and thickness of foundation ground on piping progression. Once the pipe is formed beneath the levee, hydraulic gradient upstream of the pipe tip becomes larger while that along the pipe becomes rather small. Shift of this large hydraulic gradient position to the upstream with rise of the flood water level leads to the large subsidence of the slope in the protected side and marked increase in flow rate. Repeated seepage and thickness of the permeable foundation layer have influence on stability of levee against piping. Repeated seepage makes the piping progression faster and levee vulnerable to the piping formation. With the thinner permeable foundation layer beneath the levee, the levee is at higher risk to cause brittle failure while the required hydraulic gradient to cause piping is larger.
\end{abstract}

\section{INTRODUCTION}

In recent years there is a great concern in seepageinduced failure of levee. Such a levee failure can occur when river water seeps through levee and/or foundation layer. It is difficult to identify the condition of piping progression leading to the levee breach. The 2012 Northern Kyusyu Heavy Rain caused the Yabe River levee breach without overtopping. Investigation Committee reported that this failure was caused by piping (Ministry of Land, Infrastructure, Transport and Tourism, Japan 2013). In the 2015 Kinugawa River Flood, it was also pointed that piping was one of factors that may have accelerated the levee breach (Ministry of Land, Infrastructure, Transport and Tourism, Japan 2016).

There have been many studies on piping, but many of the previous experimental studies were conducted under very simplified conditions: The piping was modelled in one dimensional seepage cell (Sugii et al. 1989, Suzuki et al. 2007, among others). The impermeable embankment was modelled by stress boundary through air bladder (Richards \& Reddy 2012) or rigid material (Van Beek et al. 2015). These simplified experiments are helpful to understand the phenomenon, but the model test mimics the realistic ground condition may be better. Recently, experimental studies with more realistic levee model were conducted (Van Beek et al. 2010, Leavell et al. 2014).
However still there is room for studying more about the piping in foundation beneath levee and studies that investigate the influence of seepage history and/or ground condition are limited. Thus, in this study, we examine how piping leading to large deformation of levee progresses by centrifuge model tests. In the tests, influence of repeated seepage and thickness of foundation ground on piping are also investigated. In addition, an attempt is made to observe the piping progression visually using a transparent model embankment.

\section{CENTRIFUGE TESTS}

Typical model levee in the centrifuge tests is shown

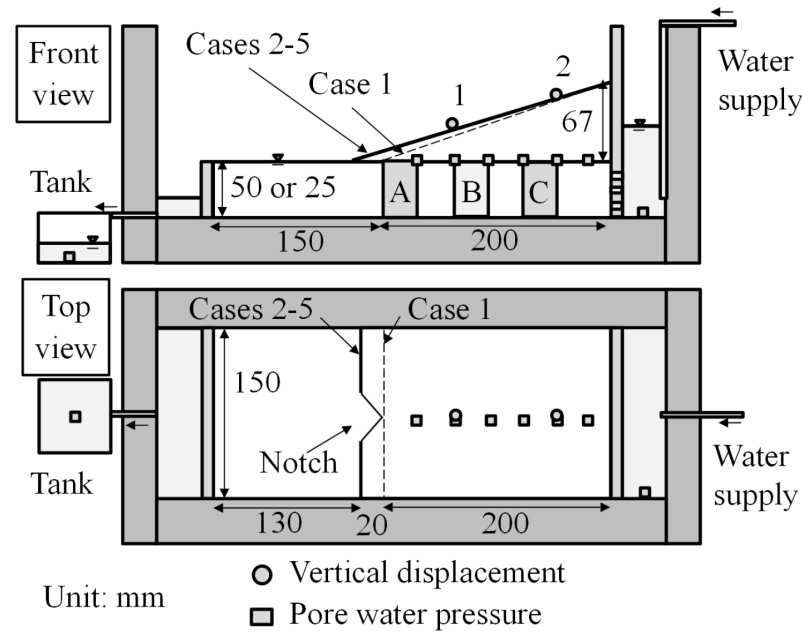

Figure 1. Model setup 
Table 1. Physical properties of Silica No. 8

\begin{tabular}{lc}
\hline Density, $\rho_{s}\left(\mathrm{Mg} / \mathrm{m}^{3}\right)$ & 2.637 \\
Mean particle size, $D_{50}(\mathrm{~mm})$ & 0.16 \\
Effective particle size, $D_{10}(\mathrm{~mm})$ & 0.087 \\
Coefficient of uniformity, $U_{c}$ & 2.09 \\
Minimum void ratio, $e_{\min }$ & 0.703 \\
Maximum void ratio, $e_{\max }$ & 1.333 \\
\hline
\end{tabular}

Table 2. Properties of Kaolin clay and jelly

\begin{tabular}{lcc}
\hline & Kaolin clay & Jelly \\
\hline Density, $\rho_{s}\left(\mathrm{Mg} / \mathrm{m}^{3}\right)$ & 2.602 & 1.07 \\
Liquid limit, $w_{L}(\%)$ & 77.5 & - \\
Plastic limit, $w_{P}(\%)$ & 30.3 & - \\
Plastic index, $I_{p}$ & 47.2 & - \\
Young's modulus, $E(\mathrm{MPa})$ & 0.13 & 0.06 \\
\hline
\end{tabular}

Table 3. Test conditions

\begin{tabular}{lccccl}
\hline \multirow{2}{*}{ Test ID } & \multicolumn{2}{c}{ Foundation } & \multicolumn{2}{c}{ Embankment } & \\
\cline { 2 - 3 } & Material & Thickness & Material & Notch at toe & Change in water level (Average hydraulic gradient) \\
\hline Case 1 & & $50 \mathrm{~mm}$ & & Without & Monotonic, $0 \rightarrow 50 \mathrm{~mm}(0 \rightarrow 0.25)$ \\
Case 2 & Silica & $50 \mathrm{~mm}$ & Kaolin & With & Monotonic, $0 \rightarrow 50 \mathrm{~mm}(0 \rightarrow 0.25)$ \\
Case 3 & No. 8 & $50 \mathrm{~mm}$ & clay & With & Repeated, $0 \rightarrow 30 \rightarrow 0 \rightarrow 43 \mathrm{~mm}(0 \rightarrow 0.15 \rightarrow 0 \rightarrow 0.22)$ \\
Case 4 & & & Welly & With & Monotonic, $0 \rightarrow 68 \mathrm{~mm}(0 \rightarrow 0.34)$ \\
Case 5 & & $50 \mathrm{~mm}$ & With & Monotonic, $0 \rightarrow 62 \mathrm{~mm}(0 \rightarrow 0.31)$ \\
\hline
\end{tabular}

in Figure 1. In the tests, only the slope on the protected side is modelled. The slope is $1 \mathrm{~V}: 3 \mathrm{H}$, which follows the recommendations on levee slope in Japan. Slope length (or seepage length) is $200 \mathrm{~mm}$ in the model scale. Thickness of the permeable foundation ground is either 50 or $25 \mathrm{~mm}$ and length of the exposed area, i.e., distance from the slope toe to the protected side boundary of the model, is either 130 or $150 \mathrm{~mm}$. Seepage test is conducted in a centrifugal acceleration field of 50G. Corresponding prototype length of the model slope is $10 \mathrm{~m}$ and the thickness of the foundation ground is either 2.5 or $1.25 \mathrm{~m}$.

In this study, expected hydraulic condition is that the river water seeps through not the embankment but the foundation ground when the flood water level rises. To meet this end, the sandy soil is used for the foundation ground to model the permeable layer, while less permeable material is used for the embankment. Based on the preliminary experiments, Silica No. 8 (Relative density $=30 \%$; void ratio $=$ 1.14; hydraulic conductivity $=9.6 \times 10^{-3} \mathrm{~cm} / \mathrm{s}$ ) is used for the model foundation ground and Kaolin clay (water content $=55 \%$; unit mass $=13.5 \mathrm{kN} / \mathrm{m}^{3}$; Unconfined compression strength, $q_{u}=14 \mathrm{kPa}$; Secant modulus at $q_{u} / 2, E_{50}=0.13 \mathrm{MN} / \mathrm{m}^{2}$ ) is used for the model embankment. In the case where an attempt is made to observe the piping progression visually, the transparent embankment made of jelly that permits visual observation of piping progression from top is used. Properties of the Silica No.8 are summarized in Table 1. Properties of the Kaolin clay and jelly are summarized in Table 2.

Rise of water level on the flood side is modelled by supplying water to the reservoir in the upstream side, as in the tests by Horikoshi and Takahashi (2015). There are two partition plates near the both sides of container as shown in Figure 1. The upstream partition plate that separates model ground from the upstream reservoir has many holes in the area contacting with foundation ground. Water can easily flow through these holes into the foundation ground. Because the upstream side partition plate is higher than the embankment, it is possible to raise the flood water level higher than the embankment height. Amount of the supplying water is controlled by the valve in the centrifuge operation room. Rising rate of the flood water level is $2 \mathrm{~mm} / \mathrm{min}$ in all the cases. Due to the limitation in the water supply, the test is terminated when the rise of the flood water level cannot be made. The downstream partition plate has no hole and the height of the plate is same as the foundation ground surface level. Existence of this downstream partition plate maintains saturated condition of the foundation ground, i.e., the ground water level is always the same as the foundation ground surface level, and amount of overflow water from the downstream boundary is monitored so that the flow rate is estimated.

The foundation ground is prepared by compaction with relative density of $30 \%$. To observe the erosion of the foundation soil visually, the coloured sands are placed as shown in Figure 1 (Areas A, B and $\mathrm{C}$ ). The model embankment is made with the Kaolin clay and is formed in the separate mould and is placed on the foundation ground before saturating the foundation ground.

In this study, five tests are performed; Case 1 is the case without notch at the middle of the slope toe, while the notch is made at the middle of the slope toe in the other cases. The shape of the notch is shown in Figure 1. In Case 3, repeated seepage is given to the model ground. In this case, the flood water level is raised until outflow of coloured sand from Area A is observed, and then the water level in the upstream side is dropped to the foundation ground surface level. The second seepage is given with the same rising rate of the flood water level. In Case 4, the thickness of the foundation ground is half of that in the other cases. In Case 5, material used for the model embankment is changed to the jelly for visual observation of the piping progression. Test conditions for all the cases are summarized in Table 3. 
Table 4. Average hydraulic gradient when coloured sand outflow from slope toe is observed

\begin{tabular}{cccc}
\hline \multirow{2}{*}{ Test ID } & \multicolumn{3}{c}{ Outflow of coloured sand from } \\
\cline { 2 - 4 } & Area A & Area B & Area C \\
\hline Case 1 & 0.158 & 0.181 & - \\
Case 2 & 0.145 & 0.161 & 0.214 \\
Case 3 & $0.147,0.114^{*}$ & $0.121^{*}$ & $0.169^{*}$ \\
Case 4 & 0.191 & 0.333 & 0.333 \\
Case 5 & 0.205 & 0.231 & - \\
\hline
\end{tabular}

*Outflow in second seepage

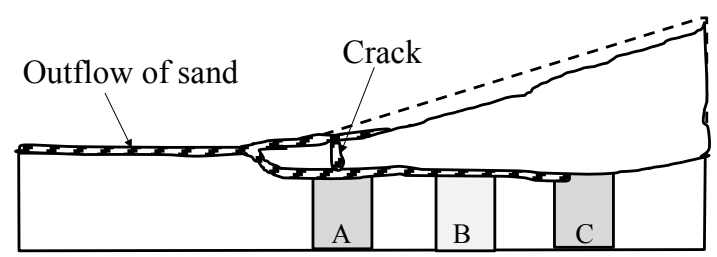

(a) Front view

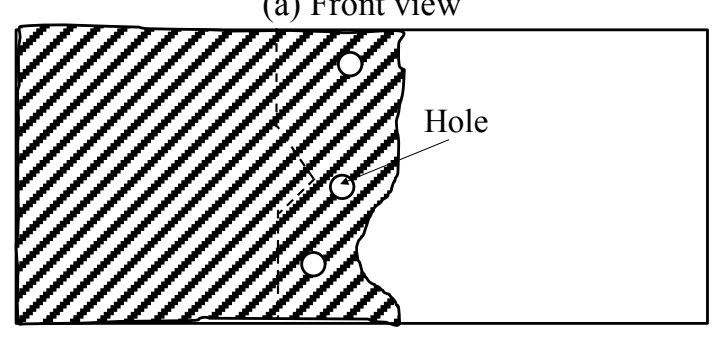

(b) Top view

Figure 2. Typical failure mode (Case 2)

Measurements of pore water pressures at the boundary between the embankment and foundation ground and vertical displacements at the middle of the slope are made during the tests. Besides the flood water level and the amount of the overflow water at the downstream boundary are also measured by pore water pressure gauges. Locations of sensors are shown in Figure 1. During the test, the top view and side view of the model ground are recorded by videos and digital camera.

\section{TEST RESULTS}

\subsection{Onset of outflow of coloured sand}

Table 4 summarizes the average hydraulic gradient when the outflow of the coloured sand from slope toe is observed. The average hydraulic gradient is calculated by dividing the water level difference between upstream and downstream by the seepage length. If this definition is adopted, according to the scaling laws for the seepage flow in the centrifuge test, apparent hydraulic conductivity of the soil is $9.6 \times 10^{-3} \mathrm{~cm} / \mathrm{s} \times 50=4.8 \times 10^{-3} \mathrm{~m} / \mathrm{s}$.

In Case 2, the average hydraulic gradient to cause the outflow of the coloured sand from Area A is smaller compared to that in Case 1. This suggests that existence of notch, i.e., weak point at the toe, may have caused increase of local hydraulic gradient around the toe and may have made onset of soil erosion earlier.
In Case 3, the average hydraulic gradient to cause outflow of the coloured sand from Area A in the second seepage is smaller than that in the first seepage. The average hydraulic gradients to cause outflow of the coloured sand from Areas B and C in the second seepage of Case 3 are also smaller compared to those in Case 2. These indicate that repeated seepage can make the levee unstable against piping.

In Case 4, the average hydraulic gradient to cause outflow of the coloured sand is much larger than that in Case 2 for all the coloured sand areas. The other noticeable difference between Cases 2 and 4 is that the required average hydraulic gradients to cause outflow of the coloured sand from Area $\mathrm{C}$ is almost the same as that from Area B in Case 4. One of the possible reasons for this is that change in the local hydraulic gradient along the seeping direction is less in the case with the smaller thickness of the permeable foundation ground. Because of this, the required average hydraulic gradient for piping is larger in the case with the thinner permeable foundation layer, but it might lead to brittle failure, i.e., quick percolation of the pipe can occur in the case with the thinner permeable foundation layer.

In Case 5, required average hydraulic gradient to cause outflow of the coloured sand are larger compared to that in Case 2. Perhaps the smaller stiffness of the jelly may have delayed the formation of the pipe in Case 5.

\subsection{Deformation pattern}

Figure 2 shows typical piping-induced failure mode observed in the tests. In all the cases except Case 4 with the thinner foundation layer, outflow of the sand in the foundation ground progressively occurs with rise of the flood water level. Loss of the sandy soil near the slope toe leads to excessive settlement of the slope toe. Because of this, cracks on the slope are formed around the toe. Through these cracks, outflow of the foundation soil also occurs and it accelerates outflow of the foundation soil with forming sand volcanos around the toe of the slope. As a result, large volume of the foundation soil flows out and the pipes percolates to the upstream, leading to the very large settlement of the entire slope.

In Case 5, unlike the other cases, translational sliding of the slope occurred with outbreak of the crack in the Kaolin clay that fills the gap between the jelly and partition plate in the upstream side. In this case, because of the smaller mass of the embankment, the percolation of the pipes to the upstream resulted in the translational sliding of the entire slope.

Figure 3 shows typical piping progression observed. In this figure, the progression in the second seepage of Case 3 is shown as an example. In Cases 2 4, similar formation of pipe is observed from 


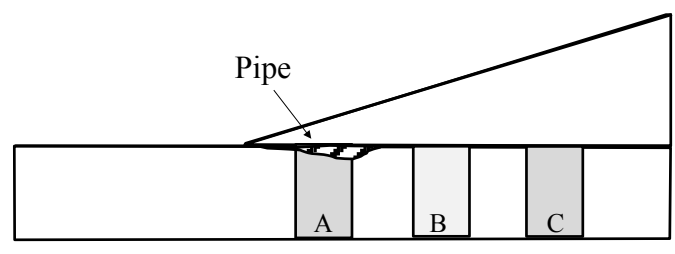

(a) Average hydraulic gradient $=0.140$

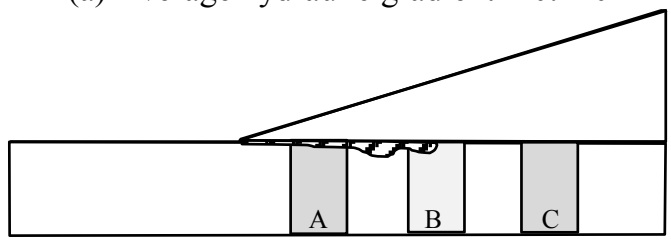

(b) Average hydraulic gradient $=0.175$

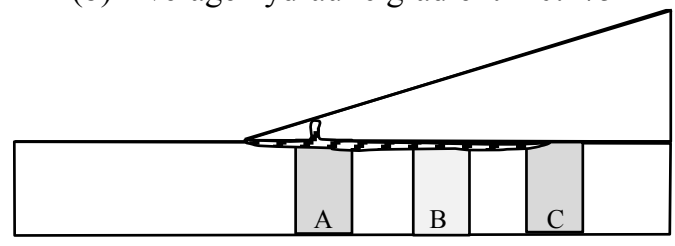

(c) Average hydraulic gradient $=0.190$

Figure 3. Observed piping progression (Case 3, front view)

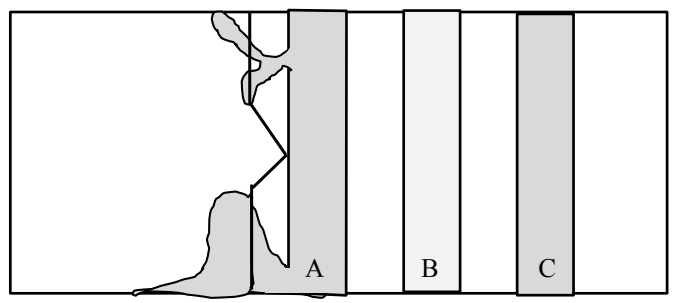

(a) Average hydraulic gradient $=0.230$

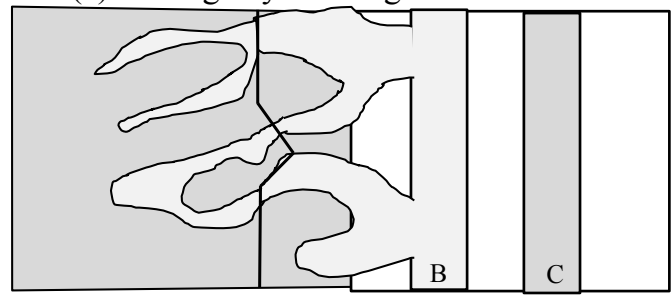

(b) Average hydraulic gradient $=0.260$

Figure 4. Flow of coloured sands (Case 5, top view)

the front transparent window. The pipe is firstly formed beneath the slope toe and propagates along the interface between the embankment and foundation ground toward the upstream with rising of the flood water level. The size of the pipe is not constant, but repeatedly shows expansion and contraction with piping progression.

Figure 4 shows flow of the coloured sands in Case 5. This observation is made through the transparent embankment. It is confirmed that the sand flow is not straight but meandering and sometimes bifurcates. It is inferred that the piping invades the weaker zone and the distribution of pore water pressure, i.e., hydraulic gradient, is not uniform in transverse direction to the seepage flow.

\subsection{Vertical displacement on slope}

Changes in vertical displacement on the slope in Case 2 are shown in Figure 5 as an example. Three vertical lines in the figure indicate the average hy-

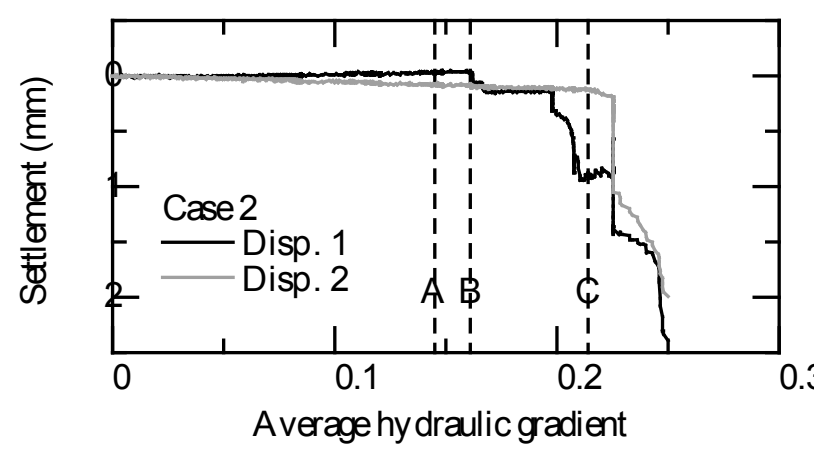

Figure 5. Vertical displacements measured at Points 1 and 2 on the slope (Case 2)

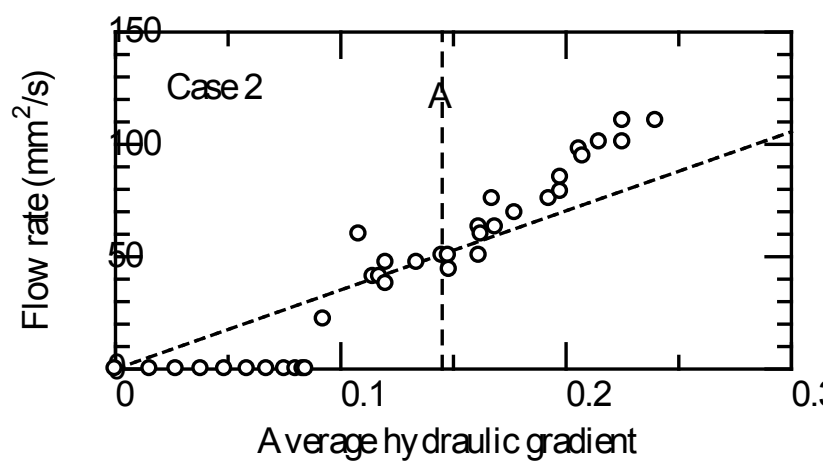

Figure 6. Change of flow rate with average hydraulic gradient (Case 2)

draulic gradient at which outflow of the coloured sand from the areas shown in Figure 1 is observed at the slope toe. In all the cases except Case 4, the vertical displacements of the slope gradually change with outflow of the coloured sands. Marked settlement is observed when the tip of the pipe reaches the middle of the slope, i.e., outflow of the coloured sand from Area B is observed at the slope toe. It can be said that the piping has influence on the stability of levee once the tip of the pipe reaches the middle of the slope.

\subsection{Flow rate}

Change of flow rate with average hydraulic gradient in Case 2 is shows in Figure 6 as an example. The flow rate is calculated by water level change in the drainage tank that collects the outflow water at the downstream boundary. The value shown in the figure is the flow rate per unit width of the model slope. A vertical line indicates the average hydraulic gradient to cause the first outflow of the coloured sand from Area A at the slope toe. The broken line is the flow rate when the seepage flow through the porous media is assumed, i.e., the flow rate without piping. If there is no pipe and water seeps through the foundation ground homogenously, the flow rate linearly increases with average hydraulic gradient as plotted with the broken line.

In all the cases except Case 4, deviation of the observation from the no-pipe condition starts around the point where the first outflow of the coloured sand is observed. Erosion of the soil beneath the 
slope toe initiates the formation of the pipe toward the upstream and its progression can also be detected by change of the flow rate with average hydraulic gradient.

\subsection{Pressure head distribution}

Distributions of pressure head at the interface between embankment and foundation around the onset of the outflow of the coloured sand from Area B for Case 2 and Case 3 in the second seepage are show in Figures 7 and 8 as examples. The slope of the plot corresponds to the local hydraulic gradient. In Cases $1 \sim 3$, it is seen that the local hydraulic gradient at the area from which outflow of coloured sand is observed decreases after observing outflow of the coloured sand from that area; For instance, the local hydraulic gradient between $x=30 \mathrm{~mm}$ and $x=90$ $\mathrm{mm}$ at the average hydraulic gradient $\left(i_{\text {ave }}\right)$ of 0.170 becomes smaller than that at $i_{\text {ave }}=0.160$ in Figure 7 . Similarly, the local hydraulic gradient between $x=$ $60 \mathrm{~mm}$ and $x=120 \mathrm{~mm}$ at $i_{\text {ave }}=0.150$ becomes smaller than that at $i_{\text {ave }}=0.122$ in Figure 8. At the same time, the local hydraulic gradient upstream to the tip of the pipe becomes larger. Shift of this large hydraulic gradient position to the upstream with rise of the flood water level leads to the large subsidence of the slope in the protected side.

\section{DISCUSSIONS}

\subsection{Influence of repeated seepage}

Pressure head distributions at the interface between the embankment and foundation ground around the onset of the outflow of the coloured sand from Area $A$ in Case 3 are shown in Figure 9. The broken lines are for the first seepage, while the solid lines are for the second seepage. It is observed that the pressure head in the second seepage is smaller compared to that in the first seepage, especially near the slope toe. Comparison of the local hydraulic gradient between $x=30 \mathrm{~mm}$ and $x=60 \mathrm{~mm}$ suggests that the pipe formed in the first seepage remains or a weak zone is formed beneath the slope toe. This may be the reason why the required average hydraulic gradient to cause outflow of the coloured sand from Area A in the second seepage is smaller than that in the first seepage in Case 3.

Changes of the flow rate with average hydraulic gradient in Case 3 are shown in Figure 10. It can be seen that deviation of the observation from the no-pipe condition (indicated by the broken line as in Fig. 6) in the second seepage starts at the average hydraulic gradient of 0.114 , which is much smaller than the average hydraulic gradient required to cause the first outflow of the coloured sand in the first seepage (0.147). From this and the local hydraulic

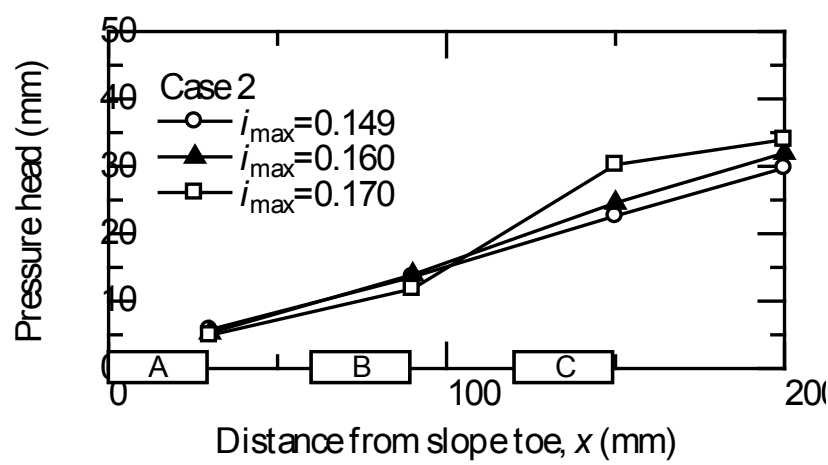

Figure 7. Distribution of pressure head at interface between embankment and foundation ground (Case 2, around onset of outflow of coloured sand from Area B)

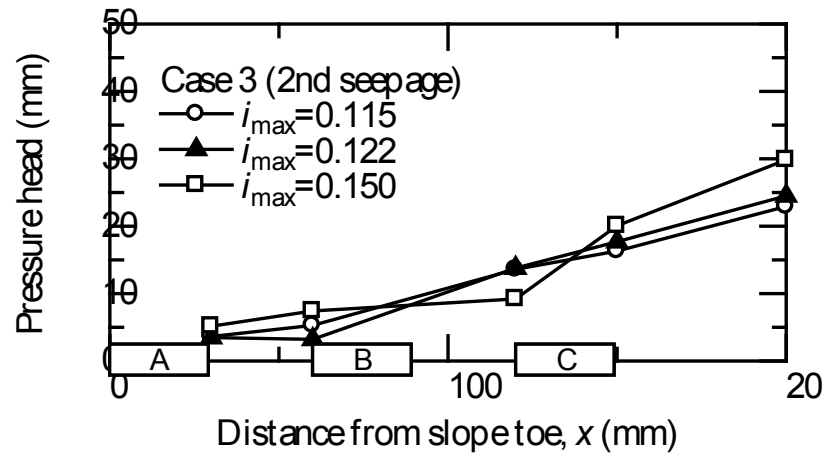

Figure 8. Distribution of pressure head at interface between embankment and foundation ground (Case 3, around onset of outflow of coloured sand from Area B in second seepage)

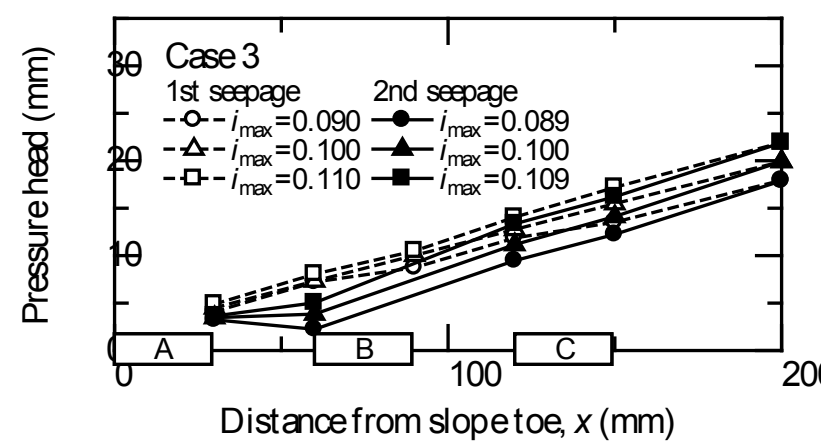

Figure 9. Distribution of pressure head at interface between embankment and foundation ground (Case 3, around onset of outflow of coloured sand from Area A)

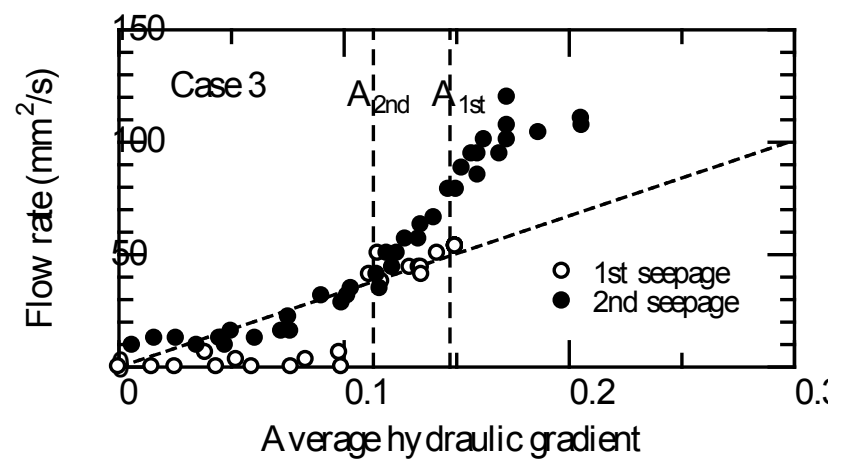

Figure 10. Change of flow rate with average hydraulic gradient (Case 3)

gradient change shown in Figure 9, it can be said that repeated seepage makes the piping progression faster and vulnerable to the piping formation. 


\subsection{Influence of thickness of permeable foundation layer}

Distributions of the pressure head at the interface between the embankment and foundation ground in Case 4 are shown in Figure 11. In contrast to the other cases, the pressure head monotonically increases with the average hydraulic gradient. Marked increase in the local hydraulic gradient cannot be seen. Because of this, the average hydraulic gradient required to cause outflow of the coloured sand in Case 4 is much larger than the other cases.

Change of the flow rate in Case 4 is shown in Figure 12. In all the cases except Case 4, marked deviation of the observation from the no-pipe condition is observed, while such tendency cannot be seen in Case 4. In Case 4, even after the first outflow of the coloured sand, amount of the sand outflow is small and no deviation of the observation from the no-pipe condition is observed before failure. As explained in the previous section, since the change in the local hydraulic gradient along the seeping direction is less in Case 4, the required average hydraulic gradient for piping is larger, resulting in the quicker percolation of the pipe and brittle failure of the slope.

\section{SUMMARY}

To examine how piping leading to levee deformation progresses and to investigate influence of repeated seepage and thickness of foundation ground on piping, centrifuge model tests were performed. From the results of experiments, the followings were drawn;

- Piping initiates with outflow of sand from the slope toe with increase in the local hydraulic gradient beneath the slope toe. The pipe gradually propagates along the interface between the embankment and foundation ground toward upstream with rising of the flood water level. Percolation of the pipes to the upstream leads to the very large settlement of the entire slope.

- Once the pipe is formed beneath the levee, hydraulic gradient upstream of the pipe tip becomes larger while that along the pipe it becomes rather small. Shift of this large hydraulic gradient position to the upstream with rise of the flood water level leads to the large subsidence of the slope in the protected side and marked increase in flow rate.

- Repeated seepage and thickness of the permeable foundation layer have influence on the levee stability against piping. Repeated seepage makes the piping progression faster and levee vulnerable to the piping formation. With the thinner permeable foundation layer beneath the levee, the levee is at higher risk to cause brittle failure while the required hydraulic gradient to cause piping is larger.

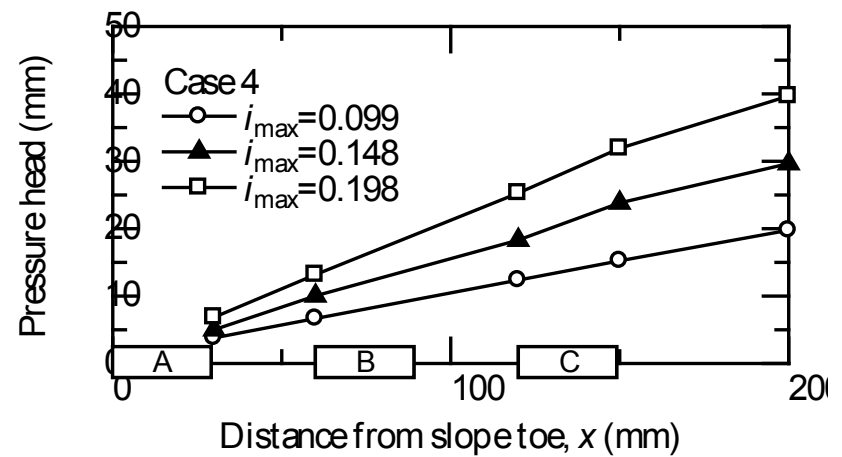

Figure 11. Distribution of pressure head at interface between embankment and foundation ground (Case 4)

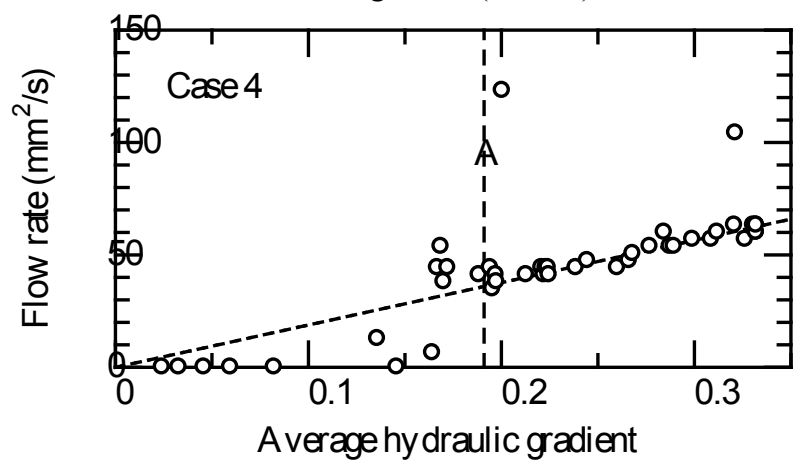

Figure 12. Change of flow rate with average hydraulic gradient (Case 4)

\section{REFERENCES}

Horikoshi, K. \& Takahashi, A. 2015. Suffusion-induced change in spatial distribution of fine fractions in embankment subjected to seepage flow, Soils and Foundations 55(5): 1293-1304.

Leavell, D.A., Wibowo, J.L., Yule, D.E. \& Strange, R.C. 2014. Geotechnical centrifuge experiments to evaluate piping in foundation soils. Technical Report by US Army Engineer Research and Development Center: ERDC/GSL TR14-14.

Ministry of Land, Infrastructure, Transport and Tourism, Japan. 2016. Report of Investigation Committee on Kinugawa River levee breach in 2015 (in Japanese).

Ministry of Land, Infrastructure, Transport and Tourism, Japan. 2013. Report of Investigation Committee on Yabe River levee breach in 2012 (in Japanese).

Richards, K.S. \& Reddy, K.R. (2012). Experimental investigation of initiation of backward erosion piping in soils. Géotechnique 62(10): 933-942.

Sugii, T., Sato, T., Uno, T. \&Yamada, K. 1989. Process of seepage failure and effect of heterogeneity in soil. Soils and Foundations 37(6): 17-22.

Suzuki, K., Motoyoshi, H. \& Oda, M. 2007. A consideration on local piping due to upward seepage flow. Journal of Japan Society of Civil Engineers Ser. C 63(2): 602-611 (in Japanese).

Van Beek, V.M., Bezuijen, A. \& Zwanenburg, C. 2010. Piping: centrifuge experiments on scaling effects and levee stability. In Springman, Laue \& Seward (eds), Physical Modelling in Geotechnics, London: Taylor \& Francis Group.

Van Beek, V.M., Van Essen, H.M., Vandenboer, K. \& Bezuijen, A. 2015. Developments in modelling of backward erosion piping. Géotechnique 65(9): 740-754. 